\title{
Two-Year Effects of a Classroom-Based Smoking Prevention and Cessation Intervention Program
}

\author{
María Teresa Gonzálvez ${ }^{a} \quad$ José Pedro Espada ${ }^{a}$ Mireia Orgilés ${ }^{a} \quad$ Steve Sussman ${ }^{b}$ \\ ${ }^{a}$ Department of Health Psychology, Miguel Hernandez University, Elche, Spain; ${ }^{b}$ Preventive Medicine/Psychology, \\ University of Southern California, Los Angeles, CA, USA
}

\section{Keywords}

Smoking cessation - Prevention - Tobacco consumption ·

Intervention

\begin{abstract}
Background: Project EX is a classroom-based smoking prevention and cessation intervention program that has been well evaluated and designed for assessing the prevention and cessation effects among adolescents in Spain. However, its long-term efficacy is still unknown. This study deals with the outcomes of a 2-year follow-up evaluation of Project EX. Methods: The intervention was tested using a clustered randomized controlled trial involving 1,546 Spanish students from 3 program schools and 3 control schools. At the end of the 2-year follow-up period, 722 subjects had completed the questionnaires (266 in the control condition and 456 in the program condition) administered to them. Results: Compared to the control condition, the program condition revealed a greater reduction in nicotine dependence ( $p=$ $0.04)$, smoking intention ( $p=0.02$ ), and in the number of cigarettes smoked during the previous month $(p=0.03)$. The CO monitor repeated assessments revealed a significant decrease of ppm levels in the program group ( $p<0.001)$. Intent-to-treat quit rates were 14.28 and $0 \%$, respectively, for the program and control conditions. Conclusions: This study
\end{abstract}

provides evidence about the long-term effectiveness of the Project EX classroom-based program for smoking prevention and cessation among adolescents in Spain.

(c) 2017 S. Karger AG, Basel

Tobacco consumption by adolescents remains an important public health problem. The World Health Organization [1] estimates that $22 \%$ of adolescents older than 15 years are regular smokers of tobacco. Although tobacco use by adolescents has declined substantially in the last 40 years, in the United States, nearly 1 in 15 high school seniors was a daily smoker in 2014 [2]. The latest survey from the European School Survey Project on Alcohol and Other Drugs [3] found that 54\% of young Europeans aged 15 years had smoked cigarettes at least once in their lifetime, and more than half of the lifetime smokers had smoked cigarettes in the last 30 days (approximately $30 \%$ of all youth); meanwhile, in the United States, only approximately $7 \%$ of high school students indicated some form of tobacco use at least once in the previous month [4]. In Spain, tobacco is the second most consumed addictive substance, with $35.3 \%$ of adolescents hooked to this habit [5]. The differences in the patterns of tobacco use between countries are evident; tobacco control is one of Spain's most pressing public health

\section{KARGER}

(c) 2017 S. Karger AG, Basel

E-Mail karger@karger.com

www.karger.com/ear
María Teresa Gonzálvez, $\mathrm{PhD}$

Department of Health Psychology

Miguel Hernandez University

Avenida de la Universidad, s/n, 03202 Elche, Alicante (Spain)

E-Mailmgonzalvez@umh.es 
needs. However, research and implementation in this regard are scarce.

Important reviews on the efficacy of smoking cessation and prevention measures among adolescents do exist [6-9]. However, only a relatively few studies on teen smoking cessation have been conducted worldwide compared to the number of adult cessation programs, and only $25 \%$ of these studies have been conducted outside the United States [10]. Also, while some tobacco use-related prevention programs have been evaluated in Spain [11], only Project EX has been well evaluated in terms of its potential for assessing the prevention and cessation effects among adolescents in Spain [12, 13]; also, this project provides motivation-coping skills-commitment material [14]. Its immediate and 1-year follow-up effects are known, but its long-term efficacy is unknown.

Project EX is an empirically validated teen tobacco use cessation program. It provides motivation-coping skillscommitment material [14]. In its clinical version, Project EX has shown 3-6-month positive outcome effects as a result of 3 experimental trials and 1 multiple baseline single group trial [15-17]. While the school-based clinical version of Project EX has been found to be effective in the United States, China, Russia, and Spain, the international translation research on Project EX thus far has been limited only to those smokers who attend the clinic. The classroom version of Project EX sought to increase the program reach and it is delivered in a classroom setting, where both tobacco users and nonusers are present. A prevention/cessation classroom-based version of EX was delivered in southern California and it was found to reveal a full range of effects on smoking, and most strongly on cessation [18].

This paper focuses on the 2-year self-reported behavioral outcomes of the Project EX prevention/cessation program conducted among Spanish adolescents. From our previous paper on the implementation and immediate outcomes of the project, it is clear that the program was well received and it revealed the immediate effects on reducing smoking intentions and CO ppm levels [12]. At the end of the 1-year follow-up, the program status revealed an outcome indicating greater reduction in nicotine dependence and CO ppm levels, and lower consumption of cigarettes during the previous month [13]. We hypothesized that the classroom-based curriculum would show the maintenance of effects among the full sample at the end of the 2-year follow-up, which would bolster the practical importance of program effects in Spain, as variations in sustained use or cessation are observed during the follow-up [19].

Project EX Spain: Prevention and Cessation Program

\section{Methods}

School Selection and Experimental Design

Before recruiting the participants, the study was first approved by the IRB at Miguel Hernandez University in order to ensure that it protects participants from any risks, involves the implementation of informed consent, and ensures maximum confidentiality of the participants. Education authorities were informed of the study goals and authorization was requested. Once such authorization was obtained, the researchers interviewed the head teachers and the school counselors and informed them verbally and in writing about the aim of the study, so as to obtain their permission and to solicit their cooperation. Finally, parents were informed by letter and requested to provide written consent for their children to participate in the study. A written parental consent was obtained for all minors who participated in this study.

We contacted a convenience sample of 45 schools from 17 towns in the Province of Alicante. After the first in-person meeting with the school boards to present the objectives of the intervention, a total of 6 high schools from 3 cities (Elche $[n=4]$, Crevillente $[n=1]$, and San Vicente $[n=1]$ ) were recruited (recruitment rate $=13 \%)$. The following are the reasons for not recruiting: no response $(72 \%)$, response after a first meeting with a statement of not being interested (18\%), and inability to be able to implement the study during the school day (10\%). The schools that were recruited for the study were randomly assigned to one of 2 experimental conditions: treatment or standard care (control) - that is, 3 schools were selected for each condition (schools were carefully matched into pairs prior to assignment on school size, and the randomization was at the level of the school) [20].

\section{Project EX Curriculum}

The original version of the Project EX prevention/cessation curriculum was translated from English into Spanish by 2 translators. Two bilingual researchers working at the University Miguel Hernandez checked the translation by reading both the English and Spanish versions. Before program implementation, the feasibility of the Spanish version was assessed by administering the Spanish version of the program to a focus group composed of 10 students in a high school. By this feasibility check, it was verified whether the curriculum was clearly understood and also whether it was culturally appropriate.

The Project EX classroom curriculum is closely adapted from the clinical program $[21,22]$. Learning activities included strategies to not start or quit smoking and learning skills for cessation maintenance, with a motivation-enhancement, interactive protocol. The program comprised several activities including (1) role playing ("talk shows"), where student volunteers filled the role of each guest and the audience (other students in class) directed their questions to the guests; (2) alternative medicine strategies including healthy breathing, characterized by slow and deep breaths, and yoga and meditation activities, which involved focusing attention on the present moment; and (3) a game, "is smoking on the menu," which divided the participants into teams to answer questions about tobacco. The curriculum involved 8 sessions delivered in classrooms (each session covering $50 \mathrm{~min}$ ) over a 6-week period. The first 4 sessions were held over a 2 -week period. The second 4 sessions were held once per week during the following month. Session 1: orientation imparted the

Eur Addict Res 2017;23:122-128 
ground rules for the class and discussed reasons for using, not using, quitting tobacco, or remaining tobacco free. Session 2: tobacco affects your life, discussed how tobacco use can cause, rather than relieve stress. Session 3: health dangers of tobacco use, discussed the harmful substances in tobacco and how it can injure one's body. Session 4: quitting step 1 - making a commitment about not using tobacco, discussed addiction to tobacco. Methods of quitting and physical and psychological aspects of withdrawal are discussed. Session 5: quitting step 2 - managing withdrawal symptoms, discussed more about nicotine, addiction, and strategies of avoiding addiction or managing withdrawal symptoms. Psychological coping included self-forgiveness and avoiding false expectations regarding how not using tobacco or quitting will and will not affect one's life. Session 6: taking care of a healthy body, involved learning lifestyle balance strategies, including weight control and practicing a "yoga activity." Session 7: taking care of your piece of mind, involved learning more coping strategies, including assertiveness training and anger management. Participants also learned the "letting feelings pass" meditation activity. Finally, Session 8: not smoking again - commitment and avoiding relapse, involved learning means to avoid using tobacco again, or staying tobacco-free, and mentioned how topics covered in the tobacco education program could be applicable to the use of other addictive substances. A more detailed description of the sessions is presented in our previous paper on the implementation and immediate outcomes of the project [12].

\section{Cultural Adaptations}

In addition to language adaptations, 5 changes were made in the curriculum to conform it to the Spanish culture. First, the original curriculum targeted "tobacco" use including smokeless tobacco, pipes, cigars, and chewing tobacco. Spanish adolescents very rarely used other forms of tobacco other than cigarettes [5, 22]; so, that information was removed and the program focused on prevention or cessation of cigarette smoking only. Second, when Project EX was implemented as a research project in the United States, extrinsic motivators were provided as incentives. Participants were told that they would obtain credits for participating in the program. In Spain, as in other international settings within which Project EX was being translated $[15,16]$, there were no incentives for attendance at the program sessions. Third, all names of characters in the talk [22] were changed from American to Spanish names. Fourth, the monetary units were changed from dollars to euros. For instance, in Session 1, "orientation," for the question "What are some reasons for quitting?" the original curriculum provided the following as a suggestion: "Save money. Over US $\$ 2,008$ per year is spent on smoking one pack per day." The amount was changed to EUR 1,249, which indicates the cost implication as relevant to the students in Spain. Finally, in Session 3, "Health Dangers of Tobacco Use," there is a question list for a game in the original curriculum pertaining to second-hand smoke and policies. Questions and forced-choice responses were changed to reflect policies in Spain. For example, one question asked "In which of the following places is it legal to smoke in the United States? ("Airline flight," "Interstate bus," "New York City taxi cab," and "None of the above")". This question was replaced with "In which of the following places is it legal to smoke in Spain? ("Airport," "Bus station," "Taxis," and "None of the above" [correct answer])."

\section{Training in Project EX}

Between October and November 2012, psychology graduate students at Miguel Hernandez University were given the opportunity to become a program facilitator. All volunteers received an introductory lecture about Project EX, which included a brief summary of the Project EX curriculum, its history, advantages of using the program, and the role of program facilitators. Seventeen Spanish graduate students ( 16 female), with average age 23 years (SD 0.8), interested in implementing the program, spent $8 \mathrm{~h}$ studying and practicing the 8 sessions of Project EX, including learning details of program delivery and how to deliver the material with fidelity. The training was provided by a researcher who had previously been trained by the program developer. Trained personnel delivered the program - an average of 2 classrooms each.

\section{Participants}

An average of 12 classes was selected per school, with a range of 8-19 classes, across the 6 high schools. A total of 1,546 students were selected for participation in the study (716 in the control condition and 830 in the program condition). Among the 1,546 subjects who participated in the pretest survey, 965 (393 in the control condition and 572 in the program condition) also completed 1 -year follow-up questionnaires (62.4\% retention rate). During the 2 -year follow-up, 722 subjects (266 in the control condition and 456 in the program condition) also completed the questionnaires (46.7\% retention rate). All adolescents who conducted assessments of baseline and 24 months follow-up were included in the analysis. Among the 722 subjects who participated in completing the 2-year follow-up questionnaires, 440 also completed the CO readings.

Participants varied from 14 to 20 years of age (mean 15.17; SD 1.20). The sample was $49.6 \%$ male $(n=358) ; 93.1 \%$ Spanish $(n=$ $672)$, and 6.9\% $(n=49)$ other nationality (e.g., South America, Morocco, Eastern Europe). Further, $81.2 \%(n=586)$ of the students lived with both parents, and $36.6 \%(n=264)$ of youths' fathers and $37.5 \%(n=270)$ of youths' mothers completed high school. Approximately $30 \%(n=216)$ of the participants had smoked a cigarette sometime in their lives and $15.2 \%(n=109)$ in the last 30 days, and $5.3 \%(n=38)$ on the day of the pretest assessment.

\section{Data Collection and Measures}

Pretest and 2-year follow-up measures were collected from students using a self-report, closed-ended and fill-in-the-blank response questionnaire, which was administered over a one class period. During the 2-year follow-up period, students who failed to return the survey were contacted by telephone for survey administration. Demographic information included age (in years), gender, nationality (born in Spain, or immigrated to Spain from another country), current living situation (with parents, live alone, other situation), and parents' education (mean response across father's [or stepfather's] and mother's [or stepmother's] educational levels) based on categories derived from Hollingshead and Redlich [23].

Smoking behavior was assessed with the fill-in-the blank item asking "How many cigarettes have you smoked in the last month (30 days)?" The level of nicotine dependence was assessed with the 8-item modified Fagerstrom Tolerance Questionnaire (mFTQ) $[15,24]$. The total score is the sum of scores on the items (range from 0 to 25). To assess smoking intention [25], students were asked the question "How likely is it that you will smoke cigarettes 
in the next 12 months?" with response categories being "1: definitely not," "2: probably not," "3: a little likely," "4: somewhat likely," and "5: very likely." Furthermore, to validate assessment-day smoking responses, the assessment of expired CO was completed at pretest and 2-year follow-up by use of a breath $\mathrm{CO}$ monitor (Micro+ Smokerlyzer; Belfont Technical Instruments, Kent, UK; http://www.bedfont.com/ch/smokerlyzer/micro, accessed April 19, 2014). Participants who responded to our 2-year follow-up telephone survey (60.94\% of the total sample at 2-year follow-up) did not complete the $\mathrm{CO}$ readings.

\section{Data Analysis}

A total of 1,546 students were selected for participation in the study (716 in the control condition and 830 in the program condition). Among the 1,546 subjects who participated in the pretest survey, 965 (393 in the control condition and 572 in the program condition) also completed 1-year follow-up questionnaires (62.4\% retention rate). All adolescents who conducted assessments at baseline and 12 months follow-up were included in the 1 -year analysis [9]. During the 2-year follow-up, only 722 participants were surveyed at pretest and follow-up (46.7\% of baseline subjects). To assess the potential sampling bias due to attrition at the 2-year follow-up across conditions (external invalidity), we calculated a new variable called "attrition group" in which we included 722 participants who were surveyed at both time points and compared them with the 824 participants who were surveyed only at pretest. We used logistic regression analysis with the "attrition group" as the dependent variable. Predictors included age, gender, nationality (born in Spain, or not), current living situation, parents' education, last month smoking, level of nicotine dependence, and smoking intention. To assess the potential sampling bias due to attrition at the 2 -year follow-up as a function of condition (internal invalidity), comparisons were made between the sample that was lost at 2-year follow-up and the rest of the sample that remained in the study at 2-year follow-up, as a function of condition with these same predictors. The comparisons utilized were chi-square or $t$ test models to indicate statistically significant differences (2-tailed $p$ value at the 0.05 level). Again, all relevant demographic and outcome variables were examined.

Data analysis for 4 outcome variables, which compared the 2 conditions, was completed with multi-level analysis [26] by using IBM SPSS Statistics 21 [27]. The outcome variables evaluated in this analysis were smoking intention, smoking behavior in the previous month, nicotine dependence (using mFTQ score), and CO readings. Condition was considered a fixed effect variable; fixed at desired experimental levels (school, considered a random effect variable). The variables adjusted for in the analyses included baseline measurements for each respective outcome variable, age, gender, status of living with both parents, and attrition propensity. The propensity for attrition score was calculated from a model predicting the actual attrition status with pretest measures [28]. The pretest measures in the attrition propensity prediction models included age, gender, ethnicity, whether or not participants lived with both parents, program condition, and cigarette use in the previous month. Two-tailed significance tests were employed for calculating the significance level in all analyses (Table 1). In an additional analysis, intent-to-treat (ITT) quit rates were calculated for those who said that they had smoked in the last 30 days on assessment day at baseline.

Project EX Spain: Prevention and Cessation Program

\section{Results}

Assessment of Attrition Bias at 2-Year Follow-Up

First, as a result of the analysis of external invalidity, differences were found only in terms of age (mean baseline age of group lost to follow-up $=15.28$ years; mean baseline age of group surveyed at both time points = $15.17 ; p<0.01)$. The attrition analysis comparing conditions (internal invalidity) revealed statistically significant differences in baseline age, smoking intention, and nicotine dependence between those who were retained at 2-year follow-up and those who were not. The participants who were followed up at 2-year follow-up in the program condition at baseline were more likely to develop an intention to not smoke in the future than in the control condition (73.2 vs. $18.3 \%$; $\left.t_{(1,429)}=6.72 ; p<0.05\right)$, and had less nicotine dependence than those in the control condition (63.4 vs. $31.1 \% ; t_{(1,932)}=13.56 ; p=0.001$ ). Differences in these variables have been controlled for in the analysis through the use of the propensity score.

\section{Effects on Smoking Intention and Tobacco Use}

As shown in Table 1, the program was found to be statistically significant in reducing smoking intention, nicotine dependence, and number of cigarettes during the previous month. Subjects in the control condition reported a higher smoking intention at the 2-year follow-up $(p=0.02)$, a higher level of nicotine dependence $(p=$ $0.04)$, and increased consumption of cigarettes $(p=0.03)$. Further, at 2-year follow-up, the $\mathrm{CO}$ monitor repeated assessments revealed a significant decrease of ppm levels in the program group $(-0.76, p<0.001)$, while the control group showed a significant increase of ppm levels $(0.37$, $p<0.001)$.

The ITT quit rate comparison was statistically significant $(p<0.05)$ among those reporting having smoked at baseline. ITT quit rates were $14.28 \%$ for program condition (16/456) and $0 \%$ for control condition (0/266). Furthermore, the baseline non-smokers did not initiate smoking at any wave of assessment (posttest, 1-year, 2 -years) in either condition of the study.

\section{Discussion}

The high rates of teenagers smoking in Spain indicate the need to develop effective long-term programs for tobacco prevention and cessation. The Project EX classroom curriculum was designed to produce smoking prevention and cessation effects all in a single program. This 
Table 1. Program effects adjusted for imbalance in attrition ${ }^{\mathrm{a}}$

\begin{tabular}{|c|c|c|c|c|c|c|c|c|c|c|}
\hline \multirow[t]{3}{*}{ Outcome variables } & \multicolumn{3}{|c|}{ Program $(n=456)$} & \multicolumn{3}{|c|}{ Control $(n=266)$} & \multicolumn{4}{|c|}{$\begin{array}{l}\text { Net effect (change in experiment - change } \\
\text { in control) }\end{array}$} \\
\hline & \multirow[b]{2}{*}{ average } & \multirow[b]{2}{*}{ SE } & \multirow[b]{2}{*}{$p$ value } & \multirow[b]{2}{*}{ average } & \multirow[b]{2}{*}{ SE } & \multirow[b]{2}{*}{$p$ value } & \multirow[t]{2}{*}{ Net } & \multicolumn{2}{|c|}{$95 \% \mathrm{CI}$} & \multirow{2}{*}{$\frac{p(\mathrm{df}=5)}{p \text { value }}$} \\
\hline & & & & & & & & lower & upper & \\
\hline \multirow{2}{*}{$\begin{array}{l}\text { Smoking intention }{ }^{\mathrm{b}} \\
\text { Smoking last month }^{\mathrm{c}} \\
\text { mFTQ nicotine } \\
\text { dependence }^{\mathrm{d}, \mathrm{e}}\end{array}$} & 1.43 & 0.08 & $<0.001^{* *}$ & 1.99 & 0.27 & 0.36 & -0.56 & -1.15 & -0.24 & $0.02^{*}$ \\
\hline & 0.56 & 0.07 & 0.45 & 0.29 & 0.24 & $<0.001^{* *}$ & 0.27 & -0.28 & 1.32 & $0.04^{*}$ \\
\hline \multicolumn{11}{|c|}{$\begin{array}{l}\text { a Adjusted for the specific outcome assessed at baseline, } \\
\text { b } 5 \text {-Point scale from definitely not (1) to very likely (5). } \\
\text { c Number of cigarettes smoked in the last } 30 \text { days. } \\
\text { d } 5 \text {-Point scale from yes, I already have (1) to no (5). } \\
{ }^{\text {e }} \text { Modified Fagerstrom Tolerance Questionnaire score. } \\
{ }^{*} p<0.05,2 \text {-tailed; }{ }^{* *} p<0.001,2 \text {-tailed. }\end{array}$} \\
\hline
\end{tabular}

study tested the 2-year effects of the prevention/cessation program among Spanish adolescents.

This study is the first to evaluate the 2-year effects of Project EX (conducted in any location), showing significant differences between program and control condition on smoking intention, nicotine dependence, and last 30day cigarette use in addition to a significant decrease of ppm levels in the program group along with an increase in ppm levels in the control group. These results confirm the hypothesis based on the results of previous studies $[12,13]$, in which we expected to find longer-term effects of the program.

Considering previous studies of Project EX, the results presented in this work are promising. With regard to Project EX tobacco use cessation, 4-month follow-up data in China indicated a $10.5 \% 30$-day quit rate and a $14.3 \% 7$-day quit rate, compared to a $3 \%$ naturally occurring quit rate in a multiple baseline design [29]. The same program in Russia [15] significantly reduced future smoking intention and intention to quit, and increased motivation to quit smoking at immediate posttest. The program resulted in a $7 \%$ quit rate during the 6-month follow-up period, compared to a $0 \%$ control group quit rate in a randomized controlled trial. In Spain, immediate outcomes of Project EX showed a reduction in future nicotine dependence scores and an increase of intention to quit smoking. At 6-month follow-up, Project EX had a significant influence on future smoking expectation and on the overall level of 30-day smoking, and approximately $14 \%$ quit in the program group versus $0 \%$ in the control group in a clustered randomized controlled trial [12].
In the classroom context, Project EX in southern California produced a greater reduction in weekly smoking and intention for smoking in the next 12 months [20]. During the 6- and 12-month follow-up periods, students in the treatment condition experienced a greater reduction in weekly smoking and monthly smoking [16]. In addition, an incremental $8 \%$ higher cessation rate was observed at the program schools [13]. In Spain, immediate outcomes of Project EX [12] showed a greater reduction in smoking intention and CO ppm levels among its participants, and 1-year follow-up outcomes revealed a greater reduction in nicotine dependence and $\mathrm{CO}$ ppm levels, and lower consumption of cigarettes during the previous month [13].

Long-term results of Project EX in Spain are relevant to clinical researchers and promoters of health education in schools, with important implication for the design of efficacious interventions to prevent and reduce tobacco use among adolescents over a relatively long time span.

\section{Limitations}

Project EX as a prevention-cessation program can effect long-term changes. Still, there are several notable limitations. First, the recruitment rate of schools was $13 \%$. Readiness to quit smoking is relatively low among Spanish adolescents and there is a low motivation among staff to add extracurricular activities to the regular school schedule. We were not able to offer the schools any incentives for participation (e.g., monetary donation to the school). Second, the dropout rate for the 2-year follow-up questionnaires was $53.3 \%$. However, we did make at least 3 attempts per school to collect follow-up data, and we 
realized that higher retention rates would be difficult to obtain. Student absentees accounted for most of the noncompletion of the questionnaires, although subject withdrawal from the study accounted for $47 \%$ of the noncompletion of questionnaires at follow-up. Students who failed to return the surveys were contacted by telephone for survey administration; only $31 \%$ of persons called could be reached and surveyed. Third, subjects who completed the survey by telephone did not complete the $\mathrm{CO}$ readings. However, concordance of results between those who completed the survey and $\mathrm{CO}$ measure suggests that youth reported honestly. Finally, US and international survey data reveal that youth are aware of e-cigarettes and use of these products in this population is rapidly increasing [30], although it is currently unregulated [31, 32]. In this study, only conventional tobacco consumption is evaluated. Future studies on the consumption or cessation of tobacco should consider using this popular type of electronic nicotine delivery system.

Recruitment and retention were major issues in the study. In Spain, it was found that a low level of readiness existed at the school levels for them to be involved in teen prevention/cessation programs. We speculate that schools simply were too overloaded with structured programming to take on a research study. It is also possible that there is a reluctance to be involved in research, or that tobacco use is perceived as low priority at the schools in the Province. May be incentives are needed to recruit schools and retain participants (particularly older participants who may be relatively likely to have competing commitments), or perhaps a longer recruitment process is needed to mobilize schools against tobacco use. Future research needs to examine these possibilities in more detail. We need to learn how to better engage schools in youth tobacco use cessation research and practice. De- spite the limitations of this study, the use of a randomized design (albeit only 3 units per condition) with a good baseline comparability, and the large sample size, the moderate likeability of the program [12], along with changes observed particularly on level of 30-day smoking and CO levels, suggest that Project EX will evolve as a promising cessation/prevention program for Spanish adolescents. Furthermore, there are no well-evaluated cessation intervention programs for adolescent tobacco in Spain; hence, the results of this study provide evidence that Project EX, a single program covering the entire Spanish adolescent population (both smokers and nonsmokers), has long-term effectiveness.

\section{Acknowledgment}

This work was supported by the Spanish Department of Economy and Competitiveness (PSI2011-26819), by the Program Valid for Research Staff training of the Council of Culture, Education and Science of the Valencian Autonomous Government (ACIF/2014/047) and a grant from the National Institute on Drug Abuse (DA020138).

\section{Human Subjects Approval Statement}

All procedures performed in studies involving human participants were in accordance with the ethical standards of the institutional and/or national research committee and with the $1964 \mathrm{Hel}-$ sinki Declaration and its later amendments or comparable ethical standards. Informed consent was obtained from all participants for being included in the study.

\section{Disclosure Statement}

All the authors declare that they have no conflicts of interest.

\section{References}

1 World Health Organization. Global Status Report on Alcohol and Health: 2014. Switzerland, 2014.

2 Johnston LD, Miech RA, O’Malley PM, Bachman JG, Schulenberg JE: Use of alcohol, cigarettes, and number of illicit drugs declines among U.S. teens. Ann Arbor, University of Michigan News Service. http://www. monitoringthefuture.org/data/14data. html\#2014data-cigs (retrieved January 12, 2015).

3 Hibell B, Guttormsson U, Ahlström S, et al: The 2012 ESPAD Report. The Swedish Council for Information on Alcohol and other Drugs (CAN). Stockholm, ESPAD, 2013.

4 Centers for Disease Control and Prevention: Tobacco product use among middle and high school students - United States, 2011 and 2012. MMWR Morb Mortal Wkly Rep 2013; 62:893-897.

5 Spanish Drugs Observatory: Encuesta estatal sobre uso de drogas en enseñanzas secundarias (ESTUDES) [National survey on drug use in high school students]. Madrid, Ministerio de Sanidad, Servicios Sociales e Igualdad, 2013.

6 Thomas RE, McLellan J, Perera R: Schoolbased programmes for preventing smok- ing. Evid Based Child Health 2013;8:16162040.

7 Grimshaw GM, Stanton A: Tobacco cessation interventions for young people. Cochrane Database Syst Rev 2006;18:CD003289.

8 Sussman S, Sun P, Dent CW: A meta-analysis of teen cigarette smoking cessation. Health Psychol 2006;25:549-557.

9 Sussman S, Sun P: Youth tobacco use cessation: 2008 update. Tob Induc Dis 2009;5:3.

10 Sussman S: International translation of Project EX: a teen tobacco use cessation program. Sucht 2012;58:317-325; erratum in 2012;59. 304. 
11 Espada JP, Orgilés M, Méndez FJ, García-Fernandez JM, Inglés CJ: Efectos del programa Saluda sobre factores cognitivos relacionados con el consumo de drogas [Saluda program effects on cognitive factors related to substance use]. Health Addict 2008;8:29-50.

12 Espada JP, Gonzálvez MT, Orgilés M, Guillén-Riquelme A, Sun P, Sussman S. Immediate effects of Project EX in Spain: a classroombased smoking prevention and cessation intervention program. J Drug Educ 2015;44: 3-18.

13 Gonzálvez MT, Espada JP, Orgilés M, Soto D, Sussman S: One-year effects of Project EX in Spain: a classroom-based smoking prevention and cessation intervention program. PLoS One 2015; 10:e130595.

14 Milton MH, Maule CO, Yee SL, Backinger C, Malarcher AM, Husten C: Youth Tobacco Cessation: A Guide for Making Informed Decisions. Atlanta, US Department of Health and Human Services, Centers for Disease Control and Prevention, 2004.

15 Idrisov B, Sun P, Akhmadeeva L, Arpawong TE, Kukhareva P, Sussman S: Immediate and six-month effects of Project EX Russia: a smoking cessation intervention pilot program. Addict Behav 2013;38:2402-2408.

16 Sussman S: A lifespan developmental-stage approach to tobacco and other drug abuse prevention. ISRN Addict 2013;2013:1-19.

17 Sussman S, McCuller WJ, Zheng H, Pfingston YM, Miyano J, Dent CW: Project EX: a pro- gram of empirical research on adolescent tobacco use cessation. Tob Induc Dis 2004;2: 119-132.

18 Sussman S, Miyano J, Rohrbach LA, Dent CW, Sun P: Six-month and one-year effects of Project EX-4: a classroom-based smoking prevention and cessation intervention program. Addict Behav 2007;32:30053014.

19 Dijk F, Reubsaet A, de Nooijer J, de Vries H: Smoking status and peer support as the main predictors of smoking cessation in adolescents from sin European countries. Nicotine Tob Res 2007;9:495-504.

20 Campbell MK, et al: CONSORT statement: extension to cluster randomised trials. BMJ 2004;328:702-708.

21 Sun P, Miyano J, Rohrbach LA, Dent CW, Sussman S: Short-term effects of Project EX4: a classroom-based smoking prevention and cessation intervention program. Addict Behav 2007;32:342-350.

22 Sussman S, Dent CW, Lichtman KL: Project EX: outcomes of a teen smoking cessation program. Addict Behav 2001;26:425-438.

23 Hollingshead AB, Redlich FC: Methodological procedures; in Hollingshead AB, Redlich FC (eds): Social Class and Mental Illness: Community Study. New York, John Wiley \& Sons, Inc., 1958, pp 18-44.

24 Prokhorov AV, De Moor C, Pallonen UE, Hudmon KS, Koehly L, Hu S: Validation of the modified Fagerström tolerance question- naire with salivary cotinine among adolescents. Addict Behav 2000;25:429-433.

25 Fagan P, Augustson E, Backinger CL, et al: Quit attempts and intention to quit cigarette smoking among young adults in the United States. Am J Public Health 2007;97:14121420.

26 Singer JD: Using SAS PROC MIXED to fit multilevel models, hierarchical models, and individual growth models. J Educ Behav Stat 1998;24:323-355.

27 IBM SPSS Statistics (Version 21) [Computer software]. IBM SPSS Statistics 21. Armonk, IBM.

28 Berger VW: The reverse propensity score to detect selection bias and correct for baseline imbalances. Stat Med 2005;24:2777-2787.

29 Zheng H, Sussman S, Chen X, et al: Project EX - a teen smoking cessation initial study in Wuhan, China. Addict Behav 2004;29:17251733.

30 Sussman S, Miyano J, Rohrbach LA, Dent CW, Sun P: Corrigendum to 'six-month and oneyear effects of Project EX4: a classroom-based smoking prevention and cessation intervention program'. Addict Behav 2010;35:803.

31 Durmowicz EL: The impact of electronic cigarettes on the pediatric population. Tob Control 2014;23(suppl 2):41-46.

32 Dutra LM, Glantz SA: Electronic cigarettes and conventional cigarette use among U.S. adolescents: a cross-sectional study. JAMA Pediatr 2014;168:610-617. 